taxa at Lufeng, and the author rightly credits his Chinese colleagues as being "far more experienced with this particular group of ramapithecines than workers anywhere else in the world" (p.92). It is thus unfortunate that these same scientists in a paper published last year, now conclude that sexual dimorphism is the most likely explanation for the observed variation at Lufeng.

Secondly, Oxnard draws comfort from the fact that each of the Lufeng subsets shows univariate distributions and multivariate patterns that could be interpreted as sexual dimorphism. But pattern is not proof, and his Fig. 5.6 is a chastening reminder of that. In that figure it appears as if the 'robust' australopithecines are dimorphic in canine breadth; indeed the shape of the histogram is familiar from the extant studies. However, the two 'sexes' are in fact geographical subsets of australopithecines. This is not to say that Oxnard's interpretation is wrong. But it does suggest that, to return to the metaphor, there is loose mortar in the foundations and there are some flaws in the design.

There are also one or two problems when Oxnard turns his attention to the fossil hominids. Although I am pleased to see a talus bone from Koobi Fora playing such a crucial role in the argument, the one he refers to, KNM-ER 813 , is most unlikely to be older than 1.8 million years. Thus, it will have to be denied its chance to star as a 4.5-million-year-old example of
Homo. Elsewhere in the book, I was intrigued by Oxnard's attitudes to cladistics. At the very beginning of the text, he adopts a 'cladistic' stance and, quite properly, warns against the unthinking pursuit of ancestors. Yet later on cladistics is roundly criticized, and yet later again his summary diagram will please cladists because it is 'ancestor-free'.

The final comments on the book must concern the "new picture of human evolution' that is its culmination. It is indeed a radical and brave proposition to suggest that australopithecines and hominines (that is, Homo) have no exclusive common ancestor. It is not such a bizarre notion as it seems; but the proposer does need to explain how the two groups come to share the characters which we presently recognize as hominid, for example reduction of the canine teeth and relative brainsize enlargement. There also have to be explanations for the characters which are apparently shared between Australopithecus africanus and Homo. However outrageous a scheme it may seem to some, it is, nonetheless, an alternative which must be considered. Cladistic studies of hominids all suggest that convergence was more common than many palaeontologists had thought. Whether, however, it is as rife as Oxnard implies in his new system remains to be seen.

Bernard Wood is Derby Professor in the Department of Human Anatomy and Cell Biology, University of Liverpool, PO Box 147 . Liverpool $L 693 B X$, UK.

\section{Simulating life's work}

\section{Michael Levitt}

Dynamics of Proteins and Nucleic Acids. By J. Andrew McCammon and Stephen C. Harvey. Cambridge University Press: 1987. Pp. 234. £27.50, $\$ 39.50$.

NIN1:T11:NT11-century philosophers would have loved this book. Starting from atoms, which are assumed to interact through simple forces and move by classical mechanics, those using molecular dynamics aim to simulate nature in all her glory, calculating with reliability the measurable physical and chemical properties of important biological molecules such as proteins and nucleic acids. Computer simulation of biological macromolecules encompasses the complete chain of reductionist thought, working up the pyramid of science from arithmetic and mechanics, through physics and chemistry, to the prediction and understanding of biological phenomena. In their preface McCammon and Harvey express their pleasure in "using Newton's laws to a book? On the one hand, there is a need for a handbook that provides an in-depth treatment of methods and results using examples to illustrate the limitations of simulation, the approximations behind the potential energy functions, and the importance of thorough analysis. On the other hand, there is a need to summarize and relate the considerable body of results, theoretical, computational and experimental, that is already available. The second path is followed in this rather slim volume, which grew out of two reviews, one by each of the authors. They have not tried to hide the book's origins, and in places it reads more like an extended review than a book.

Chapters 1 to 4 introduce the conceptual foundations and methodology. Although some effort is made to explain the methods, it is not clear that they will be easily understood by a newcomer to the field; also, for the more expert, more emphasis could have been placed on their limitations. Chapter 3, which discusses the dynamics of solvents, proteins and nucleic acids, sometimes presents facts with authority but with no supporting references; it reads more like a concluding discussion than an introduction, and this can be confusing.

Chapter 5 , one of the best in the book because of the wealth of results available, considers short-time dynamics, which can be calculated directly by molecular dynamics simulation; there is generally recognized concern that calculations done for the most part in vacuum may not give a true picture of macromolecular dynamics in solution. Chapters 6 and 7 deal with structural changes on a local and global scale, processes that take too long for direct simulation. Instead, use is made of more approximate methods, which are less satisfying than the strictly reductionist approach of molecular dynamics but do allow solvent to be taken into account.

Chapter 8 deals briefly with the dynamics of molecular associations, while the ninth and final chapter surveys future directions. The three appendices, which reproduce mathematical treatments already published in papers, are useful but the formulae (particularly those on $\mathrm{pp}$. 174-175) contain some errors.

In spite of these few misgivings, it must be stressed that this is the first book in a growing field that is of widespread interest. McCammon and Harvey's account is easily read and at the same time rewarding to those seeking deeper insight. With its comprehensive and well-balanced list of references, and its review of all the main developments, it will be an invaluable companion to those interested in the dynamics of biological macromolecules.

Michael Levitt is the $M$. and B. Levinson Professor in the Department of Chemical Physics, The Weizmann Institute of Science, Rehovot 76100, Israel. 